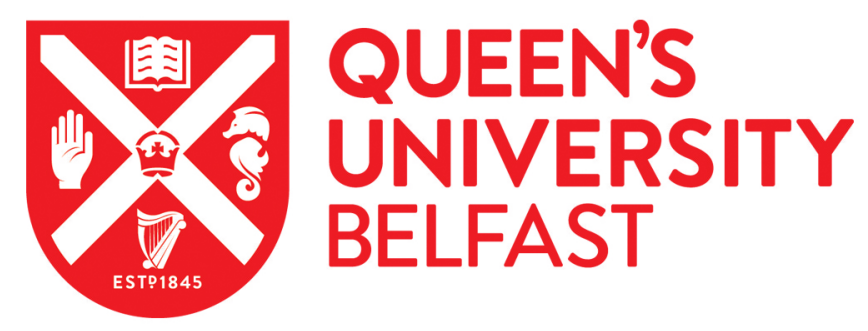

\title{
High Efficiency RF Energy Harvester for loT Embedded Sensor Nodes
}

Assimonis, S., Daskalakis, S. N., Fusco, V., Tentzeris, M., \& Georgiadis, A. (2019). High Efficiency RF Energy Harvester for loT Embedded Sensor Nodes. In IEEE International Symposium on Antennas and Propagation and USNC-URSI Radio Science Meeting - AP-S/URSI 2019 (pp. 1161-1162) https://doi.org/10.1109/APUSNCURSINRSM.2019.8888685

Published in:

IEEE International Symposium on Antennas and Propagation and USNC-URSI Radio Science Meeting - APS/URSI 2019

\section{Document Version:}

Peer reviewed version

\section{Queen's University Belfast - Research Portal:}

Link to publication record in Queen's University Belfast Research Portal

\section{Publisher rights}

Copyright 2019 IEEE. This work is made available online in accordance with the publisher's policies. Please refer to any applicable terms of use of the publisher.

\section{General rights}

Copyright for the publications made accessible via the Queen's University Belfast Research Portal is retained by the author(s) and / or other copyright owners and it is a condition of accessing these publications that users recognise and abide by the legal requirements associated with these rights.

Take down policy

The Research Portal is Queen's institutional repository that provides access to Queen's research output. Every effort has been made to ensure that content in the Research Portal does not infringe any person's rights, or applicable UK laws. If you discover content in the Research Portal that you believe breaches copyright or violates any law, please contact openaccess@qub.ac.uk. 


\title{
High Efficiency RF Energy Harvester for IoT Embedded Sensor Nodes
}

\author{
Stylianos D. Assimonis*, Spyridon N. Daskalakis ${ }^{\dagger \ddagger}$, Vincent Fusco*, Manos M. Tentzeris ${ }^{\dagger}$ and Apostolos Georgiadis ${ }^{\ddagger}$ \\ ${ }^{*}$ School of Electronics, Electrical Engineering \& Computer Science, Queen's University, Belfast, BT39DT, UK \\ Email: s.assimonis@qub.ac.uk, v.fusco@ecit.qub.ac.uk \\ ${ }^{\dagger}$ School of Electrical and Computer Engineering, Georgia Institute of Technology, Atlanta, Georgia 30332-0250 \\ Email: daskalakispiros@gatech.edu, etentze@ece.gatech.edu \\ ${ }^{\ddagger}$ School of Engineering \& Physical Sciences, Heriot-Watt University, Edinburgh, EH144AS, UK \\ Email: apostolos.georgiadis@ieee.org
}

\begin{abstract}
This work presents a high efficiency, co-planar and low-complexity RF-to-dc rectifier of one diode, which is able to be directly connected, i.e., without a matching network, to a coplanar antenna, e.g., to a dipole or loop antenna. The rectifier was designed to optimally operate at $868 \mathrm{MHz}$ and for low power input. Specifically, it presents $54.82 \%$ RF-to-dc efficiency for -20 $\mathbf{d B m}$ power input, while for $-14.4 \mathrm{dBm}$ the system is able to supply continuously, i.e., with any boost converter, a backscatter sensor node with power consumption of $20 \mu \mathrm{W}$.
\end{abstract}

\section{INTRODUCTION}

Over the last years, RF energy harvesting, i.e., the use of ambient RF power in order to supply electrical devices [1], is gaining ground, because of the rapid growing of new wireless mobile technologies, e.g., Wireless Sensor Networks (WSN), Radio Frequency Identification (RFID) and MultiInput Multi-Output (MIMO) systems. In a conventional RF harvester, an antenna captures the unused RF energy and the latter is transformed to dc through a rectification system, which consists of one or more diodes. Based on the literature [2]-[7], for low power input, the RF-to-dc efficiency, i.e., the fraction of the RF power input which finally is transformed to dc power, rarely exceed $30 \%$. In order to increase the efficiency, the losses on the rectifier should be minimized.

The contribution of this work is that proposes a new coplanar design for the rectifier, which uses only one diode (the number of the diodes increases the losses, and thus, decreases the efficiency [6], [7]) and is able to be directly connected to an impedance matched antenna, without using any extra matching network, leading to further reduction of the losses. The proposed harvester, because of its high efficiency and low-complexity, is a perfect candidate for the supply of small electrical devises, such as battery-less backscatter sensor nodes [8].

\section{RECTIFIER}

The rectifier's topology and schematic is presented in Fig. 1: it is co-planar (i.e., absence of ground plane) in order to facilitate easy connection with a co-planar antenna and consists of a single diode in series configuration with the load $R$ (capacitor $C$ is used for voltage stability), and thus, it

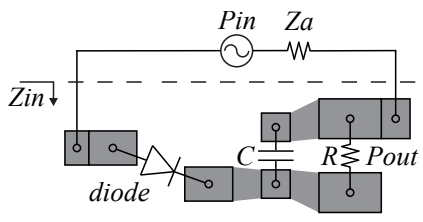

(a)

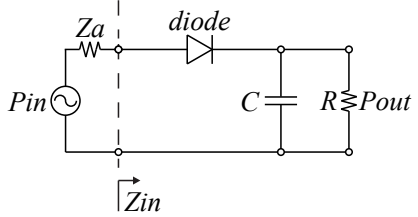

(b)
Fig. 1. The rectifier's topology (a) and circuit schematic (b): it consists of a diode in series configuration with a load, performing half-wave rectification. In this work the "HSMS285b" diode was used.

performs half-wave RF-to-dc rectification. The "HSMS285b" diode (Avago Technologies, Inc.) was chosen in our simulations, which took place through the commercial ADS software (Keysight Technologies), while for substrate the Taconic TLY$5\left(\epsilon_{r}=2.17, \tan \delta=0.0009\right)$ with thickness of $0.508 \mathrm{~mm}$ was used. The rectifier's RF-to-dc efficiency is defined as

$$
\eta=\frac{P_{\mathrm{dc}}}{P_{\mathrm{RF}}}
$$

where, $P_{\mathrm{dc}}$ is the dc power output and $P_{\mathrm{RF}}$ is the RF power input. Efficiency is a function not only of the operating frequency, but also of the power input and the load, since the structure is non-linear because of the presence of the diode. In this work, the rectifier was designed to optimally operate for low power input of $-20 \mathrm{dBm}$ at $868 \mathrm{MHz}$, taking into account the allocated UHF RFID frequencies in Europe. Thus, during the design procedure, optimization was performed with fitness function the $\eta$ and degrees of freedom the RF source impedance $Z_{a}$ and the load $R$, while frequency and power input was fixed at $868 \mathrm{MHz}$ and $-20 \mathrm{dBm}$, respectively, while $C=100 \mathrm{pF}$. Finally, the efficiency was maximized for $Z_{a}=54.6+j 707.6 \Omega$ and $R=15.4 \mathrm{k} \Omega$.

Fig. 2a depicts the efficiency versus power input: for -20 $\mathrm{dBm} \eta=54.82 \%$, while the maximum of $58.6 \%$ occurs for power input of only $-17.4 \mathrm{dBm}$. The rectifier's input impedance versus frequency for various levels of power input is depicted in Fig. 2b. It is evident that the rectifier is nonlinear and for $-20 \mathrm{dBm} Z_{i n}=54.6-j 707.6 \Omega$, and thus the source is conjugate matched with the rectifier, as expected, 


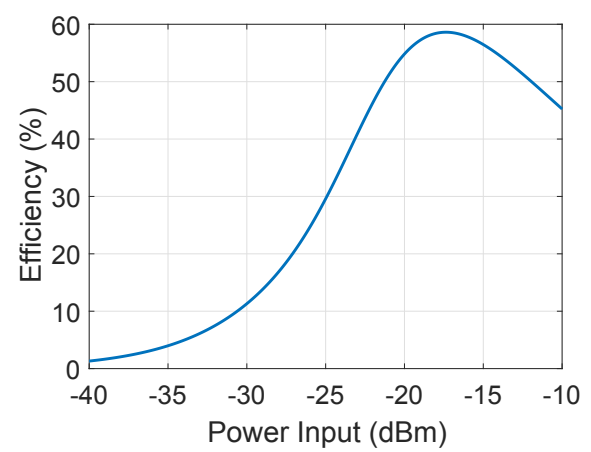

(a)

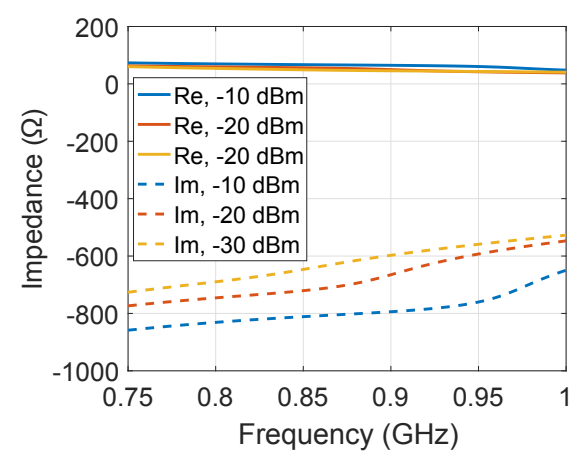

(b)

Fig. 2. Simulated rectifier's RF-to-dc efficiency versus power input at 868 $\mathrm{MHz}(\mathrm{a})$ and the real (Re) and the imaginary (Im) part of the rectifier's input impedance versus frequency for various levels of power input (b). The load $R$ at both cases is $15.4 \mathrm{k} \Omega$ and for the source is $Z_{a}=54.6+j 707.6 \Omega$.

based on the optimization procedure. Fig. 3a and 3b depicts again the RF-to-dc efficiency, but now versus frequency and load, respectively, for various levels of input power: when the frequency varies the load is fixed at $15.4 \mathrm{k} \Omega$, while when the load varies the frequency is fixed at $868 \mathrm{MHz}$. In general, for higher levels of power input the maximum efficiency takes place in higher frequency and lower output load. It is noted that in all cases the source is impedance matched with the rectifier, i.e., $Z_{a}=54.6+j 707.6 \Omega$.

\section{APPLICATION}

For $-14.4 \mathrm{dBm}$ power input the RF-to-dc efficiency is $55.41 \%$ (Fig. 2a), and thus, the rectifier serves more than 20 $\mu \mathrm{W}$ to the load. On the other hand, in [8] authors presented a backscatter sensor node with power consumption of the order of $20 \mu \mathrm{W}$. Thus, the proposed rectifier is able to supply continuously, i.e., without the use of any boost converter, battery-less backscatter sensor nodes.

\section{CONCLUSION}

In this work first presented a new, co-planar, low-complexity and very high efficiency rectifier. The latter, which is able to be directly connected to a co-planar antenna, is perfect candidate for the supply of battery-less backscatter sensor nodes, and thus for IoT applications, in general.

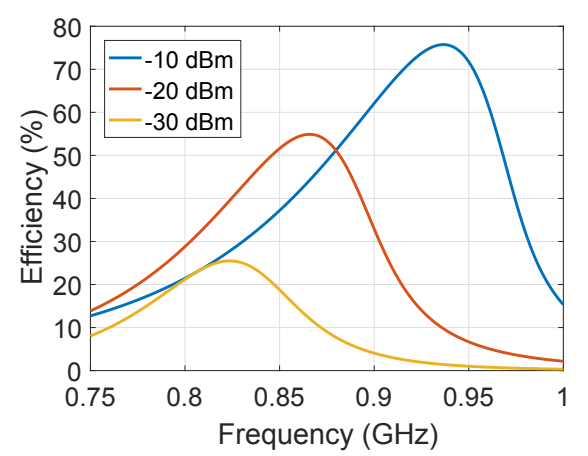

(a)

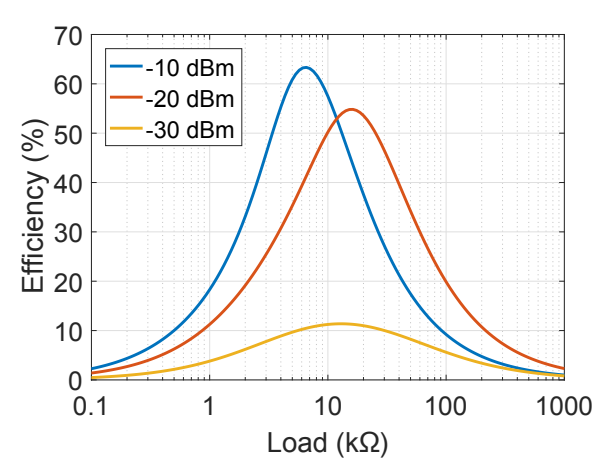

(b)

Fig. 3. Simulated rectifier's efficiency versus frequency (a) and load (b) for various levels of power input: when the frequency varies the load is fixed at $15.4 \mathrm{k} \Omega$, while when the latter varies, the frequency is fixed at $868 \mathrm{MHz}$. At both cases, $Z_{a}=54.6+j 707.6 \Omega$.

\section{ACKNOWLEDGMENT}

This work was supported by the UK Engineering and Physical Sciences Research Council (EPSRC) EP/S007954/1.

\section{REFERENCES}

[1] W. C. Brown, "The History of Power Transmission by Radio Waves," IEEE Transactions on Microwave Theory and Techniques, vol. 32, no. 9, pp. 1230-1242, Sep 1984.

[2] C. Mikeka, H. Arai, A. Georgiadis, and A. Collado, "Dtv band micropower rf energy-harvesting circuit architecture and performance analysis," in 2011 IEEE International Conference on RFID-Technologies and Applications, Sep. 2011, pp. 561-567.

[3] A. Collado and A. Georgiadis, "Conformal hybrid solar and electromagnetic (em) energy harvesting rectenna," IEEE Transactions on Circuits and Systems I: Regular Papers, vol. 60, no. 8, pp. 2225-2234, Aug 2013.

[4] S. D. Assimonis and A. Bletsas, "Energy Harvesting with a Low-Cost and High Efficiency Rectenna for Low-Power Input," in 2014 IEEE Radio and Wireless Symposium (RWS), Jan 2014, pp. 229-231.

[5] S. D. Assimonis, S. N. Daskalakis, and A. Bletsas, "Efficient RF Harvesting for Low-Power Input with Low-Cost Lossy Substrate Rectenna Grid," in 2014 IEEE RFID Technology and Applications Conference (RFID-TA), Sept 2014, pp. 1-6.

[6] — , "Sensitive and Efficient RF Harvesting Supply for Batteryless Backscatter Sensor Networks," IEEE Transactions on Microwave Theory and Techniques, vol. 64, no. 4, pp. 1327-1338, April 2016.

[7] S. D. Assimonis, V. Fusco, A. Georgiadis, and T. Samaras, "Efficient and Sensitive Electrically Small Rectenna for Ultra-Low Power RF Energy Harvesting," Scientific reports, vol. 8, no. 1, p. 15038, 2018.

[8] S. N. Daskalakis, G. Goussetis, S. D. Assimonis, M. M. Tentzeris, and A. Georgiadis, "A uw backscatter-morse-leaf sensor for low-power agricultural wireless sensor networks," IEEE Sensors Journal, vol. 18, no. 19, pp. 7889-7898, Oct 2018. 